\title{
'Narratives, Fragments and the Archeology of Authority': Exploring Supervision Experiences of Professionals Working with Domestically Abused Mentally Ill Young People
}

\author{
Dean-David Holyoake \\ School of Health and Wellbeing, University of Wolverhampton, United Kingdom \\ *Corresponding Author: d.holyoake@wlv.ac.uk
}

\begin{abstract}
This article explores the expectations made of organised supervision in health and social care settings. In particular, the way that supervision claims to be meeting the needs of the supervisee yet, is so often instructed in those of the organisation. Using the notion of conversations from supervision sessions and extracts from his ethnographic research with healthcare practitioners working with mentally ill young people and their families the author examines some of the interpersonal dilemmas practitioners encounter. His use of narrative and interpretive method allows him to reflect on how some practitioners view supervision with suspicion and as driven by systems which have no restorative characteristics as so often claimed. This exploration of supervision as a hidden site of struggle is aimed to be a starting point from which more precise questioning and testing of the possibilities of narrative type research methods could be progressed. For now, the author concludes that supervision is a site of conflict and authority because institutions use subtle messages to ensure supervisees represent expected performances and supervisors' archetypes of authority. Ethical approval for this project was granted: [LREC CA/ 5104].
\end{abstract}

Keywords Supervision, Child and Adolescent Mental Health Services (CAMHS), Care Culture, Ethnographic Research, Domestic Violence

"...the organisation within which supervision takes place has a significant impact on the supervisory relationship. The type and amount of power the supervisor exercises over the supervisee is often determined by the organization ..."

Kaiser (2004, p31)

\section{The Research had the Following Aims and Objectives}

- To emerge ethnographies exploring discourses that circulate in care cultures. In particular, those often neglected narratives which underpin the archetypes of clinical supervision.

- To assess if the implementation of ethnographic interviewing and observations in 6 psychiatric in-patient units could provide adequate data for analysis and the emergent discussion introduced in this article.

- To emerge specific themes related to the constituting sites of supervision.

\section{Introduction}

During a six year period, and as part of his doctorate, the author was a research participant in six health and social care residential in-patient services previously unknown to him. Under academic supervision and guided by complete ethical approval he participated as an additional member of the professional team over a variety of different time frames. The ethnographic approach he implemented allowed for full researcher involvement in the cultures being explored. Overall, the author had the opportunity to interview more than 50 practitioners amassing 200 in-depth ethnographic interviews using Spradley's (1979) Developmental Research Sequence and conduct in excess of 25 focus groups and 500 hours of direct participant observation. These research informants were assured full confidentiality and as a result of being shadowed by the author, trusted him enough to share their stories and have meaningful conversations about many cultural issues in their place of work. The author recorded over one hundred hours of interview data for transcription

ISSN: 2332-6840 (Online) 2332-6832 (Print) Copyright (C) 2015 by authors, all rights reserved. Authors agree that this article remains permanently open access under the terms of the Creative Commons Attribution License 4.0 International License 
related to cultural topics deemed important by the informants. In subsequent data analysis, themes began to emerge related to the experience of identity, the impact of institutional oppression and other related issues. The themes now discussed in this article use aspects of the first data sets from the author's original research.

\section{Literature (Violence and Supervision)}

The clinical arenas researched by the author are embedded in themes of violence. First, there is the domestic violence experienced by the clients and their families. Second, there is that produced as a product of therapy when clients re-experience painful memories and the dynamics of re-living trauma in its various guises and third, there is that violence generated within the institutions as a result of healthcare professionals being exposed to the woeful stories of abuse. Previous research concerning the study of violence covers a wide range of issues including the possibility of predicting causes and managing effects of domestic violence (O’Hagan and Dillenberger, 1995; Watson - Perczel et al, 1988), the statistical opportunities for treating victims (Finkelhor, 1993; Creighton and Noyes, 1989), the profiling of offender behaviour (Bibby, 1996; Fox-Harding, 1996), the effects of alcohol related violence (Graham and Wells, 2003), drug gangs (MacDonald and Marsh, 2005), adequacy of nutrition (Greene et al, 1995), wider neighbourhood influences (Garbarino and Kostelny, 1992), a lack of parent concern (Korbin, 1997) and what Jones (2001) calls factors influencing parental capacity to safeguard the child. Literature assessing the benefits of long term psychotherapeutic treatment similar to that experienced in supervision has also been conducted (Fouche and Lunt, 2010; Morrison et al, 1993; Reder et al, 1993), but these types of exploration tend to focus on outcome measurement, prediction and could enable the author the possibility of applying narrative to the experience. The worries of the Police Officer attending the family home, the duty Social Worker being called to assess the needs of a 'known family', or the healthcare professional assessing the risk and mental well being of a teenager in A and E or CAMHS (Child and Adolescent Mental Health Service).

According to Carrel and Hoekstra (2012) the nature of violence work imposes significant costs on both the victimized adult and children. Likewise, there is a cost to the institution too, in that healthcare, interagency and social care institutions recognize the importance of appropriate supervision and support for the professionals working with the victims of violence (DCSF, 2010; UKCC, 1995; 1996). Supervision aims to enable individual practitioners (i.e. supervisees) to 'develop knowledge and competence for their own practice' (Hyrkas et al, 2006; Eswaran and Malhotra, 2011). This personal, as well as professional development and growth concept remains a defining feature of supervision as noted by Butterworth's (1998) proposal that supervision is 'an exchange between professionals to enable the development of professional skills'. This allows us to see how ideas about supervision have developed during the past 25 years or so. The earlier work by Wright (1989) focuses on interaction and suggests clinical supervision is 'a meeting between two or more people who have a declared interest in examining a piece of work'. Bowles and Young (1999) evaluate the work of Cutcliffe and Proctor (1998) and the concepts of accountability, skill development and support and the effects of contract use, length of experience of clinical supervisor. Similarly Sloan et al (2000) see the cognitive aspects of structure, education, focus and collaboration as being central to supervisory integrity and in later work develop this using categories from Heron's (1989) framework to include the conception of prescription, being informative and supportive (Sloan and Watson, 2001). The issue of authenticity and tacit knowledge as researched by Nicklin (1997) points up the significance of boundaries and containment. All of these features in italic have contributed to therapeutic supervisionary qualities known as 'restorative supervision' (Teasdale et al, 2001). However, the temptation of defining and categorising supervision too simply or as anything straight forward is advised against by Yegdicht (2000) who warns with reference to Jones (1998) that 'different supervision models are difficult to reconcile at a philosophical level'. There are 'conceptual problems of simply borrowing ideas or techniques'.

Dewar and Walker (1999) developed the term 'practice driven' expectations to represent what many supervisees experience in practice. Regardless of the 'restorative narrative' many of the supervisees who shared their experiences with the author felt as though there are set ways to do things including clinical supervision which upholds what Clouder and Sellars (2004) judge to constitute a form of surveillance related to a confessional discourse similar to Gilbert's (2001) perspective of moral regulation. Under such conditions the author found that the typical claims and aspirations of supervision as having the previously mentioned far reaching benefits particularly what Sloan (1999) refers to as 'resolving discontent' were overshadowed by experiences of supervision which as describe by Platt-Koch (1986) are nothing more than a management strategy to 'inspect, direct and control'. Thus, the sanctity of the supervision experience for most of the informants is inescapably interwoven with the political and policy protocols of safeguarding legislation. So much so, that it is easy to see how the secrecy and abusive power issues of domestic violence permeates and mirrors at so many different points for the professional in supervision. As such, the author was curious to the possibility that violence as some type of fragment of abuse in an institutional setting subtly opposes, or somehow decenters the concepts of autonomy and integrity which are being increasingly promoted as being more focal to supervision practice (Berggren and Severinsson, 2003; Magnusson et al, 2002; Ogren, 2001). Thus, the author in his conversations with 
supervisees and informants began to wonder how practitioners made sense and negotiated the cultural expectations represented in these restorative and practice driven supervisory themes?

\section{Method}

Over the course of a year (and in light of his own supervising experiences) the author contemplated the typical practice driven expectations and models to do with educating, supporting and reflecting and how supervisors unwittingly produce 'archetypes of authority' which dictate the nature of the performance or game expected or prohibited in supervision sessions. These routines promote roles and function akin to that mimicked by the institution. Something oppositional to what progressive constructionist theory terms collaborative practice (Macdonald, 2007; O’Connell, 2004; Nolan and Smit, 2001). Reflexively the author had found himself 'acting out particular roles' such as 'the knowledgeable practitioner', 'the helpful advisor', 'the curious inspector', 'clever conductor' or other such like combinations typical of functional analysis. Yet, and similar to the sincere comments shared with him by the supervisees he found himself wondering if he or the supervisees could ever have the courage to push himself past what Kaiser, 2004 terms 'his personal safety zones' and into areas that 'promote growth and integrity' (Doherty, 1995)? The themes which emerged suggest that ideals of universal supervision models and practice have contributed to a narrative in which practitioners attempt to perform authentically.

\section{Discussion}

\section{Fragments of what Should and What Does Happen}

From the literature it can be seen that the aim of supervision is to restore practitioners to a point where they are reflective, autonomous and supported (as opposed to competent, programmed and conditioned). Yet it is with the latter that the notion of practice driven supervision has its roots. Most models of supervision such as that offered by Sloan and Watson (2001) emphasise interventions which are constructive, rational and driven to affirm the supervisees need to get on and do the job. They include notions such as: 'taking the lead' (demonstrating knowledge of the organisation), 'suggesting options' (demonstrating expertise), 'exploring the supervisee's work' (in an aim of improving it), 're-enacting back' (exploring new, probable and expected possibilities), 'conveying an understanding issues' (emphasising context), 'being supportive' and 'giving information' (didactic, alliances, connecting and inter-textually sited), all of which places reflective practice at the heart for all clinical supervision (Heath and Freshwater, 2000). For most of the informants in the author's research, the idea of reflection is important, because it gives the impression of choice and mastery. Otherwise, the supervisory process is mostly about what Johns (1996) terms the 'intent and emphasis of the supervisor' and the two cultural themes of the 'practice driven' and 'restorative supervision'. The following comment given to the author by Sue (Key Worker) is a typical view about the need for organizations to demonstrate 'practice driven' policies and attempt to appear 'restorative':

'...when things start to break down that's when your colleagues send you to talk to someone, not because they really think it can help, but because that's the expected thing to do and even then it's only to cover their backs'.

Similarly for John (Staff Nurse):

'...it's like you get to a point when you need to be topped up [later examined as being restored] so that you can carry on ......'

Supervisees often need to appear in control of and knowledgeable about the extreme issues they confront on a daily basis (Faller et al, 2004; Corby, 2000; Parton, 1997, 1985). Yet, it is these types of everyday and mundane issues which allow for a more in-depth analysis and holistic appraisal of supervision as a narrative. Particularly related to the extremes of social work, assessing families and domestic violence (Birchall and Hallett, 1995). For the author, the cloak and dagger feel and pretence to the expectations his supervisees had towards supervision showed themselves in two distinct categories: 'that which should happen' and 'that which actually does'. During his data collection the author was able to theorize that practitioners have ideas about their supervision that are dependent on what colleagues think about supervision including the expectation that 'good practitioners' attend supervision in order to 'reflect'. The dominant themes of reflection include the 'shocking things I have seen', the 'way I dealt with stuff', 'the awe of others opinion and practice', 'testing and comparing myself against other colleagues' and 'my advice to others is to remain detached' (Holyoake, 2011, 2000). These themes appear again and again in the supervision room. Like a game of black-jack some Social Workers and Nurses attempt to simply play without giving too much away. The process of supervision for them is nothing more than the bung or cork which legitimises and keeps the genie of pretense in the bottle. As noted by Tom (Youth Support Worker):

$$
\begin{aligned}
& \text { '...so long as I say the right things I don't get into } \\
& \text { trouble....' }
\end{aligned}
$$

This mirrors how institutional care replicates the subtle violence and warnings to contain and establish certainty. In which the child (service user) is enabled to tell their story and the professional authorized to confess theirs. Yet rendering the narrative sterile through the subtle messages of practice drivers which establish what constitutes a good practitioner: someone who is in control, logical, reasonable, not too emotional, or at least, only emotional and able to control themselves in the desired setting. Someone who knows the 
ropes (the cultural knowledge), as hinted at by Tom. However, it is a delicate balance because professionals need to maintain their reputations. Moore $(1995,1992)$ when writing about supervision reminds us of the issues professionals have to consider related to children who are at risk. The primary concerns relate to the closed systems of organisations and 'watching your back'. In addition, there is the playing of psychological games, coping with isolation, the non-sharing of information, ignoring risk factors and needing to feel safe by asking for joint visits. These few oppressing themes mirror those explored in the supervision sessions with the author.

For the typical supervisee cultural knowledge is the backdrop. Knowing the culture is significant to ones ability to survive the gulf between practice driven supervision and restorative reflective practice as noted by Richard (one of the supervisees):

'... my Manager always points to the Policies and says this is the Bible... you have to follow protocol ...but it prevents you from discussing your true and deepest concerns'.

Yet, it does appear that most organisational agendas and frameworks for making sense about such concerns are couched in a very public performance driven representation. Professionals working with victims of unimaginable experiences, such as domestic chaos and violence, have very little trust in the motives of the supervisory process (it is simply something that 'has to happen'). It was remarked to the author that this reflects the feelings domestic violence creates in anyone who comes into contact with it:

“...It's like knowing the people who give you everything can at any time slap you down and make sure you know who's really in charge.... And the minute you speak up, wham another slap..." (Tom). permits

\section{The Performance is a Delicate Balance of Fragments}

The ideas of 'fragments' developed in the authors thinking towards his research and refers to the way there is no clear cut distinctions in the experiences of supervision beyond that of the typical narrative. The ideas about what should happen, the literature and the knowing what to say is simply a façade which gives the appearance of restoration whilst representing the need for practice driven interventions. The use of ethnographic interviewing and a concern for interpreting narrative themes as a research intervention allowed for a general exploration of the often hidden and unexamined concerns neglected in much of the literature. The supervisees themselves reported issues which could quite easily be termed fragmenting concepts of 'suspicion', 'subtle testing', 'feeling lost' and a need for 'reassurance'. The publically perceived 'restorative' aim of supervision (the what should happen) runs parallel with the private 'fragmented practice driven' (what actually happens) enabled by the informal research methodology employed by the author. They are fragmenting, because as alluded to by the informants there is a realisation that the expected cultural norms do not actually sit comfortably with individual practitioners in real life. In addition, fragments allow for an analysis which is multiple, not universal, dynamic and metaphorically sharp like the 'slap' described by Tom when a colleague warns you 'to be careful', 'to watch your back', 'not to mention something', or 'make it look like you care'.

After an initial session with Sally (Youth Support Worker) the author reflected on the curious tension and suspicion that the supervision narrative generates. Sally, like many of her colleagues, explained that a lot of the time she 'turns up to supervision in body only'. There are similarities to 'going through the motions' or 'doing as little as possible' often frowned upon by managers:

'...sometimes I felt sorry for my old supervisor, so I'd turn up just make up the numbers...' (Sally).

Learning how to do the expected reflecting and identifying of key emotional issues (usually through the appropriate remark such as 'I felt angry and was keen to resolve my inner sadness, guilt....' [or any of an array of emotions here]) permits the supervisee to survive the organizational expectations. In short, the performance of reflection, as opposed to any actual reflection is the preferred option constituted by the organization which shows itself in the everyday supervision recital. For most of the informants in the authors research supervision makes it possible to avoid painful personal and moral dimensions of professional behavior by frowning upon any genuine reflection and authorship. This research theme is the realisation that supervision is less about authentic personal development but the 'acting in the expected manner':

'...it's like you have to make a decision between which is the least worst... saying what you know the supervisor wants to hear or not even bothering turning up at his office...' (Sally).

'...for someone like me [referring to low grade] you have no choice but to go and put on a brave face...' (Dave, Youth Support Worker).

And for Tim (Staff Nurse):

'...you get to a placed called numb in a long slow and unhindered manner ...' (Tim, Interview 3).

The self questioning practice of 'why can't we do supervision differently?' showed itself in his research and started the author's journey of rethinking. What are these things called restoring, reflecting, going through the motions and so on? What is the relationship that connects them to professionals, the expectations they have about themselves and each other, the institutional constraints which shackle them, train them, give them the language with which to think, communicate it and perform it? It became part of the author's quest to analyse a type of supervision which allowed professionals a realistic and authentic space in which to consider the impact their work had upon them. 
Some of the supervisee's shared how supervision is a performance which should not be too personal. In fact, some imitated that not standing out was the best way to get through it. For the author, this has connotations related to being 'anyone' and a nameless face, whereby the process of supervision positions the informant as a professional 'object' which/who is institutionally situated. In practice, this means becoming anonymous (some even yearn for this invisibility so that they don't stand out), validated and given meaning:

\section{'...I've turned up in the past and realised that I don't even know her [supervisors] name, but what's worse, they keep getting me mixed up with someone else.... You have to laugh it off...' (Mike, Community Team). \\ '...I have to work hard at not always agreeing and nodding too much...' (Sally). \\ '...this one time I said the wrong thing.... [Continues to explain] something about filling in the wrong form..... the next thing I knew my manager was marching up to me questioning why I hadn't followed procedure.... I never trusted my supervisor again because he'd obviously snitched...' (Dick, Charge Nurse/Social Worker).}

The crude fragments of non-trusting and suspiciousness is warranted in light of the experience of Dick. Yet, as a method or act of existence and acceptance there also appears to be a number of other 'fragments', stages or facets to the experience of supervision. There is a acceptance that supervision is not neutral and impermeable to the way institutions attempt to impart authority and the previously mentioned growth and integrity. Thus the pallet of archetypal authority figures have the effect of concealing a sense of solidarity, instigating a sense of defiance and separateness from the misinformed perceptions of managers and agents of the institution. As such, in a bubble of isolation most practitioners at least feel re-connected to the pool of dissolution shared by their colleagues:

'.... I used to think it was just me, but then I started to realise it was the same for everyone.... Then it became more tolerable [laughs]' (Toni, Care Worker).

\section{Archetypal Authority Figures, Witnessing and Networking}

Toni like many health and social care professionals who work with chaotic families described to the author the way her previous experience of supervision were nothing more than a management exercise:

“...at best it's a chance to sit down... It was all a bit contrived to be honest, I just said what I thought my supervisor wanted to hear so we could get it over with..."

This comment is recognisable and conceals a common theme related to 'authority' necessary in the supervisory process. These ethnographically induced concepts are bestowed 'expertness' situated in the fabric of organisations.
The author in his time has heard supervisees comment that if they are seen as not coping their managers consider them as being somehow psychologically hurting on one end of a continuum and dangerous at the other end. For example, 'transferring emotions', 'building inappropriate attachments' with the child, or simply 'fantasising and attempting to mother or infantile the relationship'. These terms are examples of violence and they circulate in care cultures, existing as symbolic messages which subtly validate professional ways to behave (they are practice drivers). The behaviours (violence, threats of, results of, reasons for) professionals experience, and subsequently respond to, may appear far-fetched to the average liberal minded person, but there is no doubt that professionals become connected (possibly in the same way as the victims of domestic violence) in the dynamic of the meaning created by each individual case and the way institutional systems circulate worth as authority. This is recognised by Sally:

“...that's when I was really in despair to be honest because what can you do? When I left I thought all of the paperwork was in place and that the girl was safe.... It turns out that even though I was not to blame I still feel guilty. It's always the same..."

The issue of 'networking' is becoming increasingly relevant. Whether the internet, the pub or long distance telephone call human beings tend to find their own method for coping. Regardless of competence of the supervisor who asks the right questions and listens in the prescribed manner there is no substitute for the equally non-expert colleague who is a simply witness, and collaborator:

'...there were a few sessions when I felt as though I was an equal, but then my supervisor left.... The thing is, at first I just went through the motions because I was told to go to supervision by my boss.... I didn't even get a choice...' (Tom).

As noted by Muncie (2005) our lives over the past 15 to 20 years seem to have become detached from core moral principles of previous generations and priority has been given to management and performance. That is, the notion of individuality and personal needs have become more and more focal. The narrative of promoting ventilation of feelings and expressing oneself is now a discourse which would have appeared very alien a generation ago. The stiff upper lip older generation would dismiss the reference to 'emotional baggage' made by Tom (above) or the 'feeling guilty' expressed by Sally as an insignificant concern for most caring roles. Therefore, in this seemingly more enlightened period the informants signal an edge or precarious balance between being too touchy-feely and embracing of the new systems rhetoric of 'individuality', 'multiverse' 'networking' and 'feelings' age.

It is within this context that the author's future research will question organization's abilities to provide supervision as standardized performance. Supervision can be researched as yet another façade, another act and a type of counselling 
management something like France (2007) might term life as a 'series of systems' needing managing. This resonates as a one size fits all, but everyone is expected to appear fashionable. The data gleaned from the supervisees shows that supervision as presented in much of the literature is a favorable narrative, but too idealistic and in need of more exploration to help disentangle the emerging fragments proposed by the author.

\section{Summary \& Recommendations}

The author set out to explore the issue of institutional supervision in care settings. Much of the literature and ideas practitioners have towards supervision is coached in an idealized notion that supervision is, or at least should be restorative. There is a recognition that some supervision is practice driven and that this creates a tension for some practitioners in that they have to represent a particular performance. One which is constituted through subtle organizational narratives. These valorize and position practitioners. In the eyes of the informants supervision firmly belongs to a discourse which means well, but doesn't always deliver. This is indicated in the performance expected of the informants and the archetypal authority of the supervisor. In terms of the research process, the ethnographic research method allowed for a different type of exploration and analysis. It allowed the informants to feel fully involved and the development of more awkward themes which challenge some of the typical and venerated impressions of supervision. In addition, the combination of explorative data collection and interpretive analytical method has given the author opportunity to pose alternative questions and emerge ungainly themes about fragments for his next sets of research. Questions about networking, collaborative practices and progressive re-evaluations of social performing.

\section{Discussion Points}

- The welfare of the staff group and training

- The way systems operate to hide and cover up stretch resources

- $\quad$ Out out of place legislation and reform

- The subject positioning of the victim is simply shifted

- The story (narrative) is now one of a shared experience and meaning

\section{REFERENCES}

Berggren, I.; Severinsson, E. (2003) Nurse supervisors' actions in relation to their decision-making style and ethical approach to clinical supervision, Journal of Advanced Nursing, 41 (6), p615622.
Bibby, P. (Ed.) (1996) Organised abuse: The Current Debate. Aldershot, Aldgate.

Birchall, E.; Hallett, C. (1995) Working Together in Child Protection. London, HMSO

Bowles, N.; Young, C. (1999) An evaluative study of clinical supervision based on Proctor's three function interactive model, Journal of Advanced Nursing, 30 (4), p958-964.

Butterworth, T. (1998) Clinical supervision as an emerging idea in nursing. In: Clinical Supervision and Mentorship in Nursing (Butterworth T., Faugier J. \& Burnard P., eds), Stanley Thornes, Cheltenham, p1-18.

Clouder, L.; Sellars, J. (2004) Reflective practice and clinical supervision: an interprofessional perspective, Journal of Advanced Nursing, 46 (3), p262-269.

Corby, B. (2000) Childabuse: towards a knowledge base. Buckingham, Open University Press.

Creighton, S.; Noyes, P. (1989) Child abuse Trends in England and Wales 1983 - 1987. London, NSPCC.

Cutcliffe, J.R.; Proctor, B. (1998) An alternative training approach to clinical supervision, British Journal of Nursing, 7 (6), p345-350.

Dewar, B. J.; Walker, (1999) Experiential learning: issues for supervision, Journal of Advanced Nursing, 30 (6), p1459-1467.

DCSF (2010) Working Together to Safeguard Children: A guide to inter-agency working to safeguard and promote the welfare of children, Department of Children, Schools and Families, London, HMSO.

Doherty, W. (1995) Soul searching: Why psychotherapy must promote moral responsibility. New York, Basic Books.

Eswaran, M.; Malhotra, N. (2011) Domestic violence and women's autonomy in developing countries: theory and evidence, Canadian Journal of Economics / Revue canadienne d'Economique, Vol. 44, 4, p1222-1263.

Faller, K. C.; Meezan, W.; Mendez, M. M.; Tropman, J.; Vandervort, F. E.; Willis, D. (2004) The Supervisor in Child Welfare. In: Supervision as Collaboration in the Human Services (Austin, M.J \& Hopkins, K.M. Eds), London, Sage, p283 - 293.

Finkelhor, D. (1993) Epidemiological factors in the clinical identification of child sexual abuse, Child Abuse and Neglect, 17, p67-70.

Fouche, C. Lunt, N. (2010) Nested Mentoring Relationships: Reflections on a Practice Project for Mentoring Research Capacity amongst Social Work Practitioners, Journal of Social Work, 10(4), p391-406.

Fox-Harding, L. (1996) Family, State and Social Policy. London, Longman.

France, A. (2007) Understanding Youth in Late Modernity, Open University Press, McGraw-Hill Education, Maidenhead.

Garbarino, J.; Kostelny, K. (1992) Child maltreatment as a Community Problem. Child Abuse and Neglect, 16, p455 - 464.

Gilbert, T. (2001) Reflective practice and clinical supervision: meticulous rituals of the confessional, Journal of Advanced Nursing 36, p199-205. 
Graham, K.; Wells, S. (2003) 'Somebody's gonna get their head kicked in tonight!' Aggression among males in bars - a question of values? British Journal of Criminology, 43, p546 - 566.

Greene, B.; Norman, K.; Searly, M.; Daniels, M.; Lubeck, R. (1995) 'Child Abuse and Neglect by Parents with Disabilities: A Tale of Two Families.' Journal of Applied Behaviour Analysis, 28, p417 434.

Heron, J. (1989) Six Category Intervention Analysis. Human Potential Resource Group, University of Surrey, Guildford.

Holyoake, D-D (2011) Is the doctor-nurse game still being played? Nursing Times, Vol 107, No 43, p12 - 14.

Holyoake, D-D. (2000) Using transactional analysis to understand the supervisory process. Nursing Standard,Vol14(33) p37-41

Hyrkas, K. , Appelqvist-Schmidlechner, K. \& Haataja, R. (2006) Efficacy of clinical supervision: influence on job satisfaction, burnout and quality of care, Journal of Advanced Nursing, 55 (4), p521-535.

Johns, C. (1996) Visualising and realising caring in practice through guided reflection, Journal of Advanced Nursing, 24, p1135-1143.

Jones, D. (2001) The Assessment of parental Capacity. In: The Child's World: Assessing Children in Need. London, Jessica Kingsley Publishers p 255-272.

Jones, A. (1998) 'Out of the sighs': an existential-phenomenological method of clinical supervision: the contribution to palliative care, Journal of Advanced Nursing, 27, p905-913.

Kaiser, T. L. (2004) Supervisory Relationships. In: Supervision as Collaboration in the Human Services (Austin, M.J \& Hopkins, K.M Eds), London, Sage, p21 - 34.

Korbin, J. (1997) Culture and Child Maltreatment. In: The Battered Child (Helfer, M.; Kempe, R.; Krugman, R. Eds) London, University of Chicago Press, p29 - 48.

Macdonald, A. (2007) Solution-Focused Therapy: Theory, Research \& Practice, London, Sage Publications

MacDonald, R.; Marsh, J. (2005) Disconnected Youth? Growing Up in Poor Britain. Basingstoke, Palgrave.

Magnusson, A.-B.; Lutzen, K.; Severinsson, E. (2002) The influence of clinical supervision on ethical issues in home care of people with mental illness in Sweden, Journal of Nursing Management, 10, p37-45.

Morrison, T.; Erooga, M.; Beckett, R, (1994) Sexual Offending Against Children: Assessment and Treatment of Male Abusers, London, Routledge.

Moore, J. (1995) Child protection: Supervision within social services departments. In: Good Practice in Supervision (Pritchard, J. Ed), London, Jessica Kingsley Publishers p 55 - 69.

Moore, J. (1992) The ABC of Child protection. Aldershot: Ashgate.

Muncie, J. (2005) The globalization of crime control - the case of youth and juvenile justice, Theoretical Criminology, 19 (1), p35 64.

Nicklin, P. (1997) A practice centred model of clinical supervision, Nursing Times, 93 (46), p52-54.
Nolan, M.; Smit, S. (2001) Maintaining quality care in the independent sector - Clinical supervision: a key piece of the jigsaw? In: Fundamental Themes in Clincial Supervision (Cutcliffe, J.R.; Butterworth, T.; Proctor, B. Eds). London, Routledge p 170 - 184.

O'Connell, B. (2004) Solution-Focused Stress Counselling, London, Sage Publications

O'Hagan, K.; Dillenberger, K. (1995) The Abuse of Women in Childcare Work. Buckingham: Open University Press.

Ogren, M.-L. (2001) Group Supervision. Learning Psychotherapy in a Small Group Format. Doctoral Thesis, from the Department of Humanities, Informatics and Social Science, Karolinska Institute, Stockholm.

Parton, N. (1997) Child protection and Family Support: Tensions, Contradictions and Possibilities, London, Routledge.

Parton, N. (1985) The Politics of Child Abuse, London, Macmillan

Platt-Koch L.M. (1986) Clinical supervision for psychiatric nurses, Journal of Psychosocial Nursing, 24, p7-15.

Reder, P.; Duncan, S.; Gray, M. (1993) Beyond Blame: Child Abuse Tragedies Revisited, London, Routledge.

Scott, E.; Hoekstra, C. M. (2012) Family Business or Social Problem? The Cost of Unreported Domestic Violence, Journal of Policy Analysis and Management, Vol 31, 4, p861-875.

Sloan, G.; Watson, H. (2001) Illuminative evaluation: evaluating clinical supervision on its performance rather than the applause, Journal of Advanced Nursing, 35 (5), p664-673.

Sloan, G. (1999) Good characteristics of a clinical supervisor: a community mental health nurse perspective, Journal of Advanced Nursing, 30 (3), p713-722.

Sloan, G.; White, C. A.; Coit, F. (2000) Cognitive therapy supervision as a framework for clinical supervision in nursing: using structure to guide discovery, Journal of Advanced Nursing, 32 (3), p515-524.

Spradley, J. (1979) The Ethnographic Interview, London Sage Publications.

Teasdale, K.; Brocklehurst, N.; Thom, N. (2001) Clinical supervision and support for nurses: an evaluation study, Journal of Advanced Nursing, 33(2), p216-224.

United Kingdom Central Council for Nurses, Midwives and Health Visitors (UKCC) (1996) Position Statement on Clinical Supervision. UKCC, London.

United Kingdom Central Council for Nurses, Midwives and Health Visitors (UKCC) (1995) Clinical Supervision for Nursing and Health Visiting, Registrars Letter 4/95, 24 January 1995. UKCC, London.

Watson-Perczel, M.; Lutzker, J.; Greene, B.; McGimpsey, B. (1988) 'Assessment and Modification of Home Cleanliness Among Families Adjudicated for Child neglect.' Behaviour Modification, 12 , p57-81.

Wright, H. (1989) Group Work: Perspectives and Practice. Scutari Press, London.

Yegdich, T. (2000) Clinical supervision, death, Heidegger and Freud come 'out of the sighs', Journal of Advanced Nursing, 31 (4), p953-961. 
Vol.3. No.2 April, 2015, pp. 82-89

Acknowledgement and confidentiality assured to all of the key Ethics: LREC CA/ 5104 informants who contributed to the authors work. 